УAK 323(470+571)

ББК 66.3(2Poc)

DOI 10.22394/1682-2358-2019-5-88-95

A.V. Safronov, Director of Municipal Budgetary Institution of Culture «Culture and Leisure Associations in the City of Tula

\section{CIVIL CULTURE FORMATION VECTORS IN THE RUSSIAN FEDERATION}

Issues of civil culture formation in the Russian Federation are investigated. Special attention is paid to the analysis of the book by American political scientist R. Putnam "Making Democracy Work." The conclusions of the scientist are tried in the Russian realities, and vectors of building a civil culture are determined. An analysis of the texts of the RF President Addresses to the Federal Assembly since 2016 is drawn.

Key words and word-combinations: civic culture, civic education, civic culture of youth, R. Putnam, Presidential Address.
А.В. Сафронов, директор мунииипального бюджетного уиреждения культуры «Культурно-досугољое обгединение», г. Тула (email: Safmaster@yandex.ru)

\section{ВЕКТОРЫ ФОРМИРОВАНИЯ ГРАЖААНСКОЙ КУАЬТУРЫ В РОССИЙСКОЙ ФЕАЕРАЦИИ}

Аннотация. Исследуются проблемы формирования гражданской культуры в Российской Федерации. Особое внимание уделено анализу книги американского политолога Р. Патнэма «Чтобы демократия сработала». Выводы ученого проверяются в российских реалиях и определяются векторы построения гражданской культуры. Проводится анализ текстов посланий Президента РФ Федеральному Собранию РФ с 2016 г.

Ключевые слова и словосочетания: гражданская культура, гражданское воспитание, гражданская культура молодежи, Р. Патнэм, Послание Президента РФ.

$\mathrm{H}$ арастание проявлений гражАанской активности в Российской Федерации, в основном протестного характера, явицось отмичительной особенностью 2019 г. СреАи таких акций - противодействие жителей Екатеринбурга возведению храма Российской Православной Џеркви; затяжная акция жителей поселка Шиес Архангельской обмасти против строитемьства мусорного помигона; массовые митинги и акции помитических активистов и граждан Москвы и Санкт-Петербурга «За честные выборы» в преААверии ЕАиного Аня голосования 8 сен- 
тября 2019 г.; акщии солидарности с политическими активистами, находящимися в местах заключения в рамках так называемого «Московского дела». Все перечисленные события и аналогичные им проходят в условиях нарастания недовольства обществом проводимой политикой власти, падением уровней доверия и одобрения к институтам государства. Так, по данным аналитиков

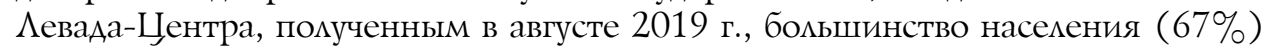
одобряет деятельность мишь Президента России В.В. Путина; не пользуются подАержкой граждан деятельность председателя Правительства РФ А.А. МеАведева (63\%), Правительства России, как такового (55\%), Государственной Аумы России (60\%). Меньше половины населения (49\%) считают, что дела в стране идут в верном направлении [1] .

В рейтинге доверия жителей разных стран к общественным институтам и институтам власти исследовательской компании Edelman, опубликованном каналом РБК, Россия заняла последнее место по общему уровню доверия и находится в конце списка в большинстве разделов доклада. Всего в опросе приняли участие более 33 тыс. человек из 28 стран мира. Компания Edelman фиксировала их отношение к властным институтам, СМИ, общественным организациям и бизнес-сообществу. Результаты показали, что в перечне стран по общему уровню доверия к институтам Россия занимает последнее место (индекс доверия 29 из 100). Отметим, что в начале 2018 г. индекс доверия в Российской Федераџии составцял 36 пунктов, поэтому страна также оказалась среди Аидеров по уровню падения за год.

«Россияне оказались на последнем месте уровня доверия к общественным организациям: им в стране доверяют мишь $23 \%$ опрошенных по сравнению с $74 \%$ в Китае, $59 \%$ в Канаде и $47 \%$ в Великобритании. То же касается и бизнеса: предпринимателям в России верят мишь $34 \%$ опрошенных (80\% - в Китае, 58\% - в Бразилии, 44\% - в Испании). Посмеднее место Россия занимает и по уровню доверия к СМИ. Медиа в России полностью доверяют только 26\% человек (на 9\% меньше, чем в прошлом году). Единственный раздел доклада, в котором Россия не заняла последнее место, - доверие к правительству. ВАастям доверяют $34 \%$ россиян - больше, чем в Мексике, Франции, Бразилии и ряде прочих стран. Вместе с тем уровень доверия к правительству в России упал сильнее всего: за гоА показатель снизился сразу на 10\%» [2] .

Очевидно, что в таких условиях власти необходимо в ближайшей перспективе предпринимать комплекс мер, направленных на устранение не посцеАствий народного неАовольства в виде увеличиваюшегося количества акций протеста со стороны населения, а причин этих проявлений, выраженных в ряде проблем. На наш взгляА, таких проблем несколько, но главной явмяется низкий уровень гражАанской культуры российского общества. ПоА гражАанской культурой понимается комплекс знаний, ценностей, норм и установок, усваиваемый мичностью в процессе социализаџии при условии свободного доступа к получению и трансляџии соџиально значимой информации, обусмовливающей поведение гражданина как субъекта гражданского общества в целом и местного самоуправления в частности, а также опредемяющий спо- 
собы взаимодействия между чиенами гражданского общества в целях эффективного функщионирования демократических институтов и базирующийся на историческом опыте государства и нации. Производные по причине низкого уровня развития гражданской культуры проблемы таковы. Во-первых, отсутствие консолидированной наџионацьно ориентированной элиты и качества аАминистрирования политических процессов. В настоящее время наблюдаются преимущественно бюрократические связи внутри вертикаци власти, построенные на принципе ее фактического наличия, но не фактической эффективности. Во-вторых, Аисфункщионализм эмиты, связанный, с одной стороны, с непопулярностью принятия волевых политических решений, а с Аругой - с отсутствием публичной Аискуссии по вопросам развития государства и общества. В-третьих, отсутствие практики широкой общественной Аискуссии, порождающее абсентеизм и препятствующее демократической конкуренции во власти. В-четвертых, в сознании элиты и общества в целом не присутствует комплекс гражАанских принципов, которые Аолжны опреАелять соџиальную Аеятельность индивида. В-пятых, воспроизводство гражАанских принџипов находится в зачаточном состоянии, поскольку институты формирования гражАанской культуры (семья, институты образования, религии, местного самоуправления, СМИ и Ар.) Аействуют малоэффективно.

Указанные проблемы находятся в спектре внимания ряда Аеятелей политической науки, изучавших проявления гражданской культуры в обществе. К таковым можно отнести Р. Инглхарта («Модернизация, культурные изменения и демократия») [3], А. Аейпхарта («Аемократия в многосоставных обществах») [4], Р. Аамя («Проблемы гражданской компетентности») [5] . В рамках Аанной статьи остановимся подробнее на труде Р. Патнэма «Чтобы демократия сработала» [6], опубцикованном в 1996 г. На основании результатов исследования автор заключиц, что группа северных регионацыных правительств Итации оказалась гораздо успешнее своих южных сосеАей, суАя по показателям соџиально-экономического развития, гражданского участия, Аоверия к институтам вцасти и т.п. Ценность работы Р. Патнэма состоит в том, что, экстраполируя полученный им научный опыт анализа принципов реализации ценностей гражданской кумьтуры в разных регионах Италии на современные российские реалии, в южной части страны можно выявить проблемы, аналогичные Аля России, при этом северная часть показала обратный результат.

Ученым было установлено, что население северных регионов Италии неизменно демонстрировало большую гражданскую активность в отличие от соотечественников-южан. Так, граждане северных территорий Италии активно интересуются политикой и участвуют во всевозможных общественных объединениях, а жителей южных регионов «влечет к урнам не идея, но привязанность к патрону. Отсутствие гражкаанских ассоциаций и малочисленность местных среАств массовой информации означают, что дела общин вершатся в стороне от гражАан» [6, с. 100]. Примечательно, что Р. Патнэм использует термин «гражданская культура» без кавычек, принимая его за устоявшееся понятие [6, с. 155] .

Анализируя успешность северной Италии, американский политолог пишет о факторах развития сообшеств: «КАючевую роль в успехе индустриальных 
округов играют нормы взаимности и система гражданской вовлеченности. Поощряется поток информации по технологическим проблемам, по кредитоспособности потенциальных партнеров, по деловым качествам работников и т.А. Прогресс определяется постоянным информационным взаимодействием в кафе, в барах, на умицах. Социальные нормы, утверждающие частный интерес в ущерб сообществу, здесь настолько подавлены, что почти не работают. В качестве основных черт этих индустриальных округов, состоящих из миниатюрных фирм, наблюдатели отмечают взаимное доверие, общественное сотрудничество, высокоразвитое чувство гражданского долга - иначе говоря, главные качества гражданского сообщества» [6, с. 163]. Р. Патнэм делает вывод, что влияние гражданского сообщества приоритетно и превосходит фактор экономического развития, то есть кучше живут те регионы, где крепче гражданские традиции.

Исследователь подчеркивает несколыко важных особенностей развития гражданской культуры: вовлеченность, консенсус и информаџионное взаимодействие, где информация явцяется необходимым условием гражданской культуры. Именно поэтому гражданская культура преАставцяется достаточно активным конструктивным взаимодействием государства и гражданского общества, а также взаимодействием институтов гражданского общества межАу собой и с отдельными жкителями или их объединениями. Предполагается, что общество и государство совместно должны создавать такие институты и правила, в рамках которых могли бы урегулироваться возникающие конфиикты на основе приеммемых (разделяемых) Аля обеих сторон ценностей и интересов. При отсутствии противоречий с гражданским обществом государство выполняет функщии арбитра и координатора деятельности граждан, соџиальных групп и объединений на основе установленных норм и процедур, которые если и могут пересматриваться, то при взаимодействии обеих сторон и в эволюџионном режиме. В целом гражАанская культура выступает в роли интегратора государственных и негосударственных форм проявления и организаџии общественной жизни.

Р. Патнэм отмечает историческую природу сложившейся диспропорџии в «гражданственности» регионов: «Несмотря на вихрь перемен, именно регионы, которые в конце XX века отмичаются особой гражданской вовлеченностью, были теми регионами, где в XIX веке в изобилии имелись кооперативы, культурные ассоџиации и общества взаимопомощи, а в XII веке ассоџиаџии соседей, гильдии и религиозные братства, которые обеспечивали процветание коммунальных республик. Хотя эти “гражданственные” регионы сто мет назаА не были особо передовыми, именно они намного опередици менее "гражданственные” регионы как в экономических успехах, так и (по крайней мере, с возникновением региональных правительств) в качестве управления» [6, с. 164] .

Взаимосвязь исторических традиций в культурном процессе с успехами или неудачами государств отмечали и другие исследователи политической науки. Работа политологов С. Хантингтона и $\Lambda$. Харрисона «Культура имеет значение», опубликованная в 2000 г., преАставцяет собой сборник статей, посвященных результатам анализа вцияния культуры на развитие остальных сфер жкизни государства и общества во многих странах [7]. В издании удемено внимание и Рос- 
сии: «Семьдесят пять мет антирыночной и антибуржуазной пропаганды насаАили крайне враждебное отношение к частной иниџиативе. Ааже сейчас, когда

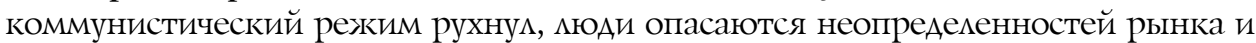
уповают на скуку государственного попечения. Они предпочитают равенство в бедности, присушее земледельческим культурам по всему миру» [7] .

Обратим внимание на Аругой, теперь уже положительный, пример из истории укрепления гражданской культуры в Японии, приведенный в сборнике. Объясняя причины, по которым Япония в XIX-XX вв. совершияа невероятный экономический прорыв, А. Аандис подчеркивает: «Японџам присуще острое чувство групповой ответственности: у них считается, что нерадивый работник вредит не только себе мично, но и всей семье. Аалее, разумеется, важнейшую роль сыграло национальное чувство японцев. Раньше, во времена клана Токуга-

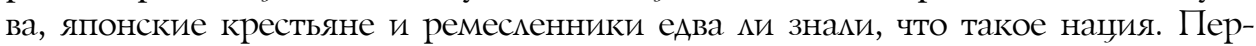
вейшая задача нового императорского государства заключалась именно в том, чтобы воспитать в подАанных чувство глубочайшего долга переА императором и страной и связать этот патриотизм с трудом. Значительная часть школьных программ была посвящена изучению этики; в стране, не имеющей устойчивых церковных традиций, школа выступала храмом добродетели и нравственности. Учебник 1930 года излагал это следующим образом: “Самый простой способ стать патриотом заключается в том, чтобы дисциплинировать себя в повсеАневной жизни, способствовать поддержканию порядка в семье и Аобросовестно выполнять свои производственные обязанности"» [7]. В Аополнение к этому $\Lambda$. Харрисон в статье «Способствуя преобразованиям в культуре» приходит к выводу, что еАинственное по-настоящему серьезное различие между Японией и многими Аругими странами состоит в следующем: японских детей приобщают к прогрессивным ценностям, а в иных государствах - нет [7]. Есть $\Lambda и$ конкретные шаги со стороны российской политической элиты в направцении повторения японского успеха, предстоит разобраться далее.

При анализе российских политических реалий можно констатировать, что исторически существовавшее отсутствие условий Аля бизнес-инициативы и проявления плюрацизма мнений, а также господствующее доминирование установки на патернацизм явцяются причинами крайне низких темпов развития гражданской культуры в государстве.

Осознание и принятие этих негативных факторов научным сообществом, политической элитой и, в конечном итоге, населением, будет способствовать началу положительного сАвига в процессе формирования гражданской культуры. Этап гражданского воспитания молодежи может стать первичным звеном стратегии, которая домжна строиться на цели демократизаџии всех сфер жизни социума. Аля этого необходимо, во-первых, закрепить соответствующий категориальный аппарат в нормативных актах и программных документах. Во-вторых, требуется разработка воспитательного и обучающего комплекса, направленного на формирование навыков критического мышиения, собственной позиџии, рефлексии, солидарности. В-третьих, важным условием является внедрение системы социологических замеров, отражающих уровень развития гражжанской культуры. 
Актуальность решения названных проблем подтверждает анализ Посланий Президента РФ Федеральному Собранию РФ в 2016 [8], 2018 [9] и 2019

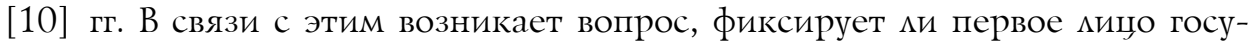
Аарства пробцемы, связанные с функционированием гражданского общества, особенно вопросы доверия и гражданского воспитания. САова «воспитание» и «воспитывать» упоминались В.В. Путиным в Послании 2016 г. Ава раза (нравственность и культура исследовательской, инженерной работы); в 2018 г. - два раза (здоровье и природа) и в 2019 г. (воспитание детей без риска бедности) - один раз. Эти слова употреблялись не в контексте гражданского воспитания и, что более важно, не в контексте артикуцяџии проблемы гражАанской культуры. Слова «доверие» и «доверять» упоминались трижАы в Послании 2016 г. (Ава раза в контексте внешней политики и один раз в контексте делового сообщества); дважды в 2018 г. (внешняя политика) и в 2019 г. единожды (внешняя политика). Слово «проблема» использовалось Президентом РФ в Послании 2016 г. тринадцать раз. В.В. Путин говорил о проблемах сферы заравоохранения, третьих смен в школах, свалок, экономики, сельского хозяйства, соџиальной сферы, мировой торговли. В 2018 г. Президент РФ употребил слово «проблема» также тринадџать раз, затронув темы минимального размера оплаты труда, демографии, детских садов, развития городов, Аоступности жилья, свалок, креАитов Амя бизнеса, развития АПК, Алительного управцяемого полета планируюшего крылатого блока ракеты. В 2019 г. В.В. Путин использовал слово «проблема» уже девятнадџать раз, но ни разу в контексте гражданского общества, участия, активности, диалога, инициативы, культуры. Аидер страны говорил о проблемах яслей, демографии, бедности. профессионализма работников соџиальной сферы, доступности медиџинских учреждений, мусора, экологии, ремонта школ, экономики в џелом, ограничения свободы и иниџиативы предпринимательства, судебного преследования бизнеса, устаревшей нормативной базы, неразвитости законоАательства, регулируюшего бизнес-сферу.

Вместе с тем в Посланиях Президента РФ затрагивались темы важности сплоченности общества, нравственности, справедиивости, солидарности, широкого пространства для свободы, консолидации общества, включенности граждан в дела страны. ОАнако никаких соответствующих рассуждений или поручений, связанных с обеспокоенностью первого миџа государства уровнем развития этих явлений в России, не последовало.

Отметим также, что Послание 2016 г. содержало довольно объемную часть, посвященную развитию школьного образования. В частности, В.В. Путин поАчеркнул: «В школе нужно активно развивать творческое начало, школьники Аолжны учиться самостоятельно мыслить, работать индивидуально и в команде, решать нестандартные задачи, ставить переА собой цели и добиваться их, чтобы в будущем это стало основой их благополучной интересной жизни» [9]. ОАнако Президент РФ установил рамки допустимых изменений: «ЗАесь очень много экспериментов в школе проводится, и за рубежком, и у нас; надо быть, конечно, очень аккуратными с этими экспериментами, но Авигаться впереА, безусловно, нужно» [9] . 
По нашим наблюдениям, с 2016 г. в общеобразовательных организациях не произошио никаких реформ, связанных с наказом В.В. Путина. Ао общества не было доведено планов Министерства образования и науки Российской Федерации ни по поводу обсуждения или внедрения проектов развития творчества, интенсификации самостоятельной и коммективной работы школьников, ни о развитии таких качеств, как гражданское участие, ответственность, бизнес-инициатива, критическое мышяение, чувство справедливости, солидарности и доверия.

Аругим Аокументом, позволяющим сделать выводы относительно масштабов и глубины заинтересованности государства в проџессе развития гражданской культуры, явцяется Стратегия развития воспитания в Российской Федераџии на период до 2025 года [11]. Ее изучение подтверждает отсутствие описания проблемной ситуации. В Стратегии как рамочном документе утверждаются положения декларативного характера, при этом не предполагается никаких конкретных решений. ОАнако обратим внимание на два пункта: «развитие и совершенствование федеральной, региональной и муниџипальной нормативной правовой базы реализации Стратегии» и «формирование системы мониторинга показателей, отражающих эффективность системы воспитания в Российской Федерации». Аокумент утвержден распоряжением Правительства России 29 мая 2015 г., но до настоящего времени нет сведений о системе мониторинга показателей эффективности воспитания, а также об ином федеральном нормативном документе, посвященном гражданскому воспитанию.

Сегодня по федеральным СМИ регулярно транслируется внешнеполитическая повестка. Широко обсужАаются вопросы обороноспособности госуАарства, взаимоотношений с сосеАними странами, мокальные конфмикты, тогда как проблемам развития гражданского общества внимания уделяется крайне мало, хотя стратегическим ресурсом роста государства явцяется именно человеческий капитал, а не тактические решения дипломатии.

Все перечисленные обстоятельства свидетельствуют о слабой заинтересованности государства в решении проблемы формирования гражданской культуры: формально она артикулируется в той или иной степени, но фактически отсутствует последовательность как в суждениях на эту тему, так и в соответствующей политике и в подведении результатов. Вместе с тем существуют определенные перспективы способности общественных институтов оказать реальное содействие формированию гражданской культуры. Подтверждение тому - круглый стол Экспертного центра Всемирного русского народного собора «Измерение ценностной солидарности и уровня общественного доверия в современном российском обществе», состоявшийся 12 февраля 2019 г., в рамках которого прошка презентаџия первых данных одноименного исследования, проводимого соџиологической группой ЦИРКОН по заказу Экспертного института социальных исследований. По словам руководителя проекта И. Задорина, в привычной методике соџиологических замеров есть изъяны: "Доверие и ценности как таковые "мерят" уже давно. ОАнако все известные на сегодняшний день методики предполагают Аишь количество “Аоверяющих" и “разделяющих” единиц. В проекте исследовательский взгляд уходит глубже: как сказать об отношении россиян Аруг к

94 Bulletin of the Volga Region Institute of Administration • 2019. Vol. 19. № 5 
Аругу с точки зрения ценностей, которые они разделяют и факторов, которые, наоборот, их отталкивают Аруг от Аруга» [12]. Согласно результатам исслеАования, $57 \%$ респондентов полагают, что в России существуют несогласие и разобщенность, а в отношении мюдей следует быть осторожными (65\%). Значительная часть опрошенных считают, что наиболее острые противоречия и конфликты возникают межАу вмастью и народом (45\%), а также богатыми и бедными (40\%). Вместе с тем $65 \%$ россиян утверждают, что в их ближнем кругу есть доверие и сплоченность, а $75 \%$ респондентов готовы объединяться Аля совместных действий. Следовательно, существует значительный потенциал Аля развития гражАанской культуры и гражданского общества. Обществу и государству необходимо прикладывать всесторонние усилия Аля укрепления доверительных горизонтальных связей как между чценами соџиума, так и межАу населением и институтами.

Таким образом, в российском обшестве сегодня необходим баланс межАу проявлениями патернализма, который так или иначе обусловливает ошибочные действия государства и стимулирует рост протестных настроений у населения, и процессом поиска возможностей Аля развития гражданской культуры в дискуссионном, нормативном и воспитательном контекстах. В случае несоблюдения равновесия есть определенный риск, с одной стороны, усиления антагонизма власти и общества, с Аругой - опасного роста популизма, что в условиях слабой гражданской культуры может привести к соџиальнополитическому кризису.

\section{Библиографический список}

1. Одобрение институтов власти. URL: https://www.levada.ru/2019/08/29/odobrenie-institutov-vlasti-16/

2. Тадтаев Г. Россия заняла последнее место рейтинга доверия к общественным институтам. URL: https://www.rbc.ru/society/22/01/2019/5c4632139a7947d392889cfd

3. Инглхарт P., Вельцель $K$. Модернизация, культурные изменения и демократия: Последовательность человеческого развития. М., 2011.

4. Лейпхарт А. Демократия в многосоставных обществах. М., 1997.

5. Даль Р.A. Проблемы гражданской компетентности. URL: http://www.politnauka. org/ library/teoria/dahl.php

6. Патнэм Р. Чтобы демократия сработала. М., 1996.

7. Хантингтон С., Харрисон Л. Культура имеет значение. URL: http://www.msps.su/ files/2010/12/Wer_culture-matters1a.pdf

8. Послание Президента РФ Федеральному Собранию РФ. URL: http://www.kremlin.ru/ events/president/news/53379

9. Послание Президента РФ Федеральному Собранию РФ. URL: http://www.kremlin.ru/ events/president/news $/ 56957$

10. Послание Президента РФ Федеральному Собранию РФ. URL: http://www.kremlin.ru/ events/president/news/59863

11. Стратегия развития воспитания в Российской Федерации на период до 2025 года: распоряжение Правительства РФ от 29 мая 2015 г. № 996-p. URL: https://rg.ru/2015/06/08/vospitanie-dok.html

12. Экспертный центр ВРНС обсудил механизмы солидарности российского общества. URL: https://vrns.ru/expert-center/5071 